\title{
Occupational and environmental exposures, the association with chronic sinusitis
}

Feras M. Alkholaiwi, MD, Rahaf R. Almutairi, Medical student, Danah M. Alrajhi, Medical student,

Basma A. Alturki, Medical student, Atheer G. Almutairi, Medical student, Faris H. Binyousef, MD.

\begin{abstract}
الأهداف : إيجاد العلاقة بين التعرضات البيئية والمهنية وحدوث التهاب الجيوب الأنفية المزمن إلجداد العاف

المنهجية : تم استخدام PRISMA في المراجعات المنهجية للبحث للعثبت فئور

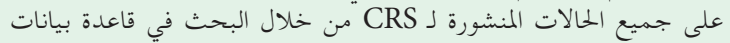
عoogle Scholar g PubMed

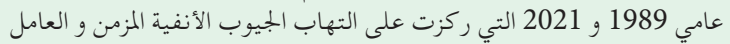

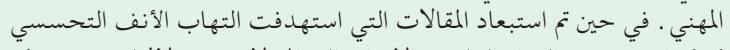

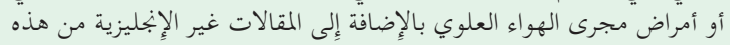

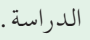

النتائج : تمت مراجعة خمسة عشر مقالاً بعد استبعاد 19 مقالة حيث أنها

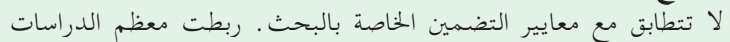

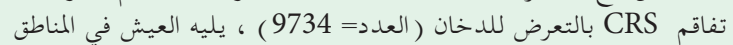

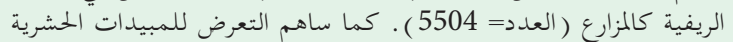

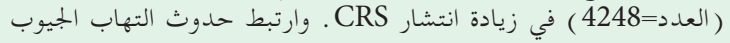

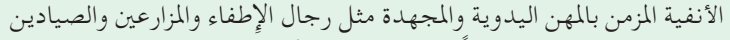

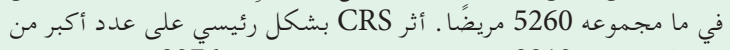

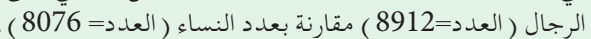

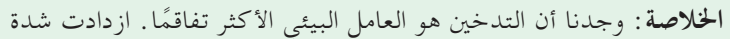

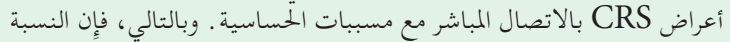

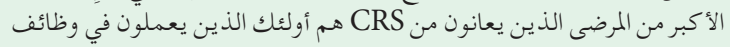
يدوية مجهدة مثل رجال الإطفاء والمزارعين والصيادين.
\end{abstract}

Objectives: To find the association between environmental and occupational exposures and chronic rhinosinusitis (CRS) development.

Methods: The Preferred Reporting Items Of Systematic Reviews Guidelines were used when a systematic literature review was conducted to find all published cases of CRS by searching PubMed database and Google Scholar. Published articles between 1989 and 2021 that reported chronic and occupational rhinosinusitis were included. However, articles that reported allergic rhinitis or upper airway diseases and non-English articles were excluded from this study.

Results: A total of 97 articles were extracted initially, and 15 articles were reviewed after excluding 82 articles that did not match our inclusion criteria. Most studies linked CRS development to smoke exposure $(n=9734)$, followed by living in rural areas as farms $(n=5504)$. Exposure to pesticides $(n=4248)$ contributed to a higher prevalence of CRS. Bluecollar occupations, such as fire fighters, farmers, and fishermen were significantly related to CRS development in a total of 5260 patients. Chronic rhinosinusitis mainly affected more men $(n=8912)$ than women $(n=8076)$.

Conclusion: We found that smoking was the most aggravating environmental factor. Chronic rhinosinusitis symptoms' severity increased with direct contact with allergens. Thus, the greatest proportion of patients with CRS was those with bluecollar occupations, such as firefighters, farmers, and fishermen.

\section{PROSPERO ID: 287176}

Keywords: sinusitis, nasal polyps, occupational exposure, environmental exposure

Saudi Med J 2022; Vol. 43 (2): 125-131

doi: 10.15537/smj.2022.43.2.20210849

From the Department of Otorhinolaryngology-Head and Neck Surgery (Alkholaiwi), College of Medicine, Imam Mohmmad Ibn Saud Islamic University; from the Collage of Medicine (Almutairi, Alrajhi, Alturki, Binyousef), Imam Mohammad Ibn Saud Islamic University, Riyadh; and from Unaizah Collage of Medicine (Almutairi) Qassim University, Kingdom of Saudi Arabia.

Received 24th October 2021. Accepted 26th December 2021.

Address correspondence and reprint request to: Dr. Rahaf Almutairi, Collage of Medicine, Imam Mohammad Ibn Saud Islamic University, Riyadh, Kingdom of Saudi Arabia. E-mail:DrRahafAlmutairi@gmail.com IRCID ID: https://orcid.org/0000-0001-6030-9606 
$\mathrm{C}^{1}$ hronic rhinosinusitis (CRS), one of the most common chronic diseases, is a condition of chronic inflammation of the paranasal sinus mucosa that lasts for at least 12 consecutive weeks, ${ }^{1}$ and is characterized by at least 2 of the following symptoms: facial pressure, pain or fullness, headache, nasal obstruction, clear or mucopurulent nasal discharge, and anosmia or hyposmia. ${ }^{2}$ The prevalence of CRS in Saudi Arabia is $25.3 \%$, and its increase has been recorded in the past few years, particularly in the Eastern Province. ${ }^{4}$ Chronic rhinosinusitis is classified into 2 categories depending on the presence or absence of nasal polyps and a clinical assessment can be employed to distinguish these two categories: CRS with nasal polyps and CRS without nasal polyps. ${ }^{5}$ There are several other subtypes, such as dental sinusitis, fungal sinusitis, and pediatric CRS. ${ }^{4}$ It is evident that CRS is associated with impaired quality of life, decreasing work productivity, and costly medical treatments. ${ }^{6}$ The pathophysiology of CRS has drawn a lot of attention, leading to an increasing number of studies investigating the risk factors associated with CRS. ${ }^{7-9}$ There are two studies of the Korea National Health and Nutrition Examination Survey that identified several risk factors, such as septal deviation, allergic rhinitis, and influenza vaccination. Moreover, there was an increase in the prevalence of CRS in machinery and plant workers, and with occupational exposure to several factors such as dust, gases, and fumes. ${ }^{10}$ When patients with occupational rhinosinusitis expose continuously to the causal agents, their conditions may worsen leading to asthma; accordingly, it is important to study the etiology of CRS, specially occupational rhinosinusitis. ${ }^{11}$ Lastly, the relationship between exposure to occupational risk factors and the development of CRS still remains unclear. ${ }^{12}$ Thus, this systematic review study is designed to build on previously published studies by expanding the number of studies to find the association between environmental and occupational exposures and CRS development. The findings of these studies may raise the awareness and enhance knowledge concerning the environmental and occupational risk factors in patients with CRS, and these factors may be taken into account when evaluating them to prevent further exacerbations. Moreover, this may also help in planning occupational safety. Additionally, these results may also facilitate a

Disclosure. Authors have no conflict of interests, and the work was not supported or funded by any drug company. better understanding of the epidemiology of CRS and provide valuable information for its prevention.

Methods. A systematic literature review was carried out to find all published cases of CRS, using the Preferred Reporting Items of Systematic Reviews guidelines by searching PubMed database and Google Scholar. Examination of the studies was carried out by 6 investigators (F.M.K., R.R.M., B.A.A., D.M.A., A.G.M., and F.H.B.) in a specific manner to prioritize determination, and to compare the significant articles. The search was carried out in June 2021 with the following terms: "chronic rhinosinusitis" and "occupation," "sinusitis" and "environmental factors." Details of the included and excluded articles are provided in Figure 1.

We included all published articles between 1989 and 2021 that reported CRS and occupation, including the following data: age, gender, number of participants with and without CRS, type of environmental and occupational exposure, method of CRS diagnosis, symptoms of CRS, and type of intervention. The articles that reported allergic rhinitis or upper airway diseases were excluded. Non-English articles were excluded from this study.

Results. We reviewed 15 research papers after excluding 82 articles that did not meet our inclusion criteria. A total of 17476 patients were diagnosed with CRS. Most studies linked CRS development to smoke

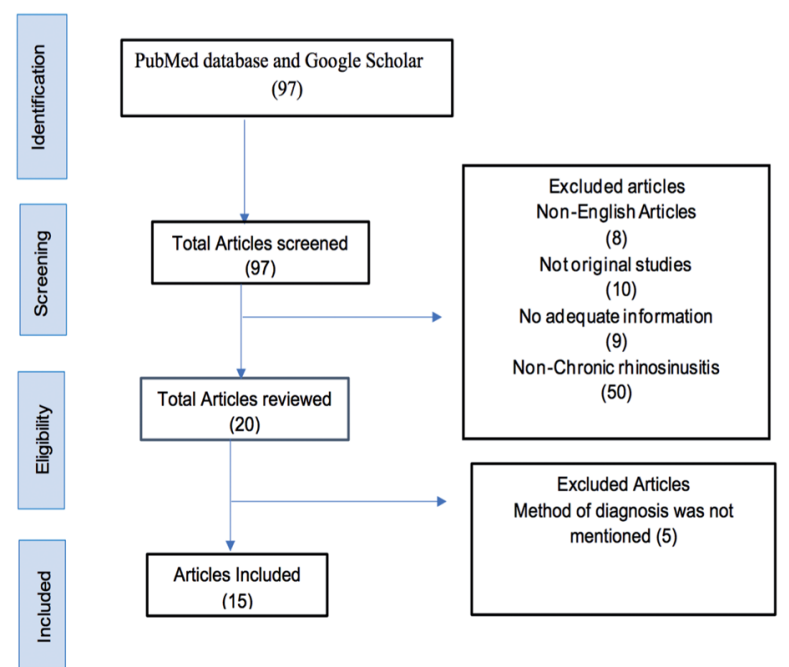

Figure 1 - The PRIMSA diagram details our selection process applied during the overview. 
exposure $(\mathrm{n}=9734)$, followed by living in rural areas as farms $(n=5504)$. Exposure to pesticide $(n=4248)$ contributed to a higher prevalence of CRS. Blue-collar occupations, such as firefighters $(\mathrm{n}=2353)$, farmers, and fishermen $(\mathrm{n}=1184)$ were significantly related to the development of CRS in a total of 5260 patients in comparison to 1176 patients with CRS with white-collar occupations, such as sales and service workers $(n=320)$ and managers $(n=136)$. Details of the environmental and occupational factors and the method of diagnosis are provided in Table 1. CRS predominantly affected more men $(n=8912)$ than women $(n=8076)$. The average age of CRS diagnosis was around 40 years; 14 years was the minimum age of CRS diagnosis and 101 years was the maximum age.

Discussion. We carried out a systematic review study of the association between CRS and occupational and environmental factors that can lead to CRS which is a prevalent disease considered as inflammation of the upper airway in the paranasal sinus mucosa that lasts for several weeks. ${ }^{1}$ CRS is characterized by symptoms including nasal obstruction / blockage/ congestion or nasal discharge (anterior/posterior nasal drip or purulent throat mucus), facial pain/pressure, and anosmia/ hyposmia, which last at least 3 months. ${ }^{1,2}$ There were

Table 1 - Characteristics of the included studies in terms of number of patients,method of diagnosis and exposure to environmental and occupational factors.

\begin{tabular}{lcll}
\hline Reference/year & $\begin{array}{c}\text { Number of } \\
\text { patients }\end{array}$ & Diagnosis methods & Occupation and environmental exposure \\
\hline Gao et la, ${ }^{1}$ & 851 & Diagnosis based on EPOS ${ }^{1}$ & Clearance-related job (32 patients with CRS), poisonous gases (58),
\end{tabular}

2016

Homood et al, ${ }^{3} \quad 219$

2017

Hussein et al,

2019

262

Diagnosis based on a survey that included 20 questions to investigate the sociodemographic and risk factors of chronic sinusitis. Criteria for patient selection was not mentioned

Diagnosis based on EPOS

\begin{tabular}{|c|c|c|}
\hline $\begin{array}{l}\text { Clarhed et al, } \\
2018\end{array}$ & 1326 & Questionnaire based on EI \\
\hline $\begin{array}{l}\text { Ahlroth Pind } \\
\text { et al,13 } \\
2017\end{array}$ & 415 & Diagnosis based on EPOS \\
\hline Hwang et $\mathrm{al}^{14}{ }^{14}$ & 1501 & Diagnosis based on EPOS \\
\hline
\end{tabular}

2018 animal fur and having pets at home (154), carpet at home or in the workplace ( 51 patients with CRS), ${ }^{2}$ air conditioner ( 439 patients with CRS who exposed to air conditioning less than 3 days/week, and 208 patients who exposed 3-6 days/week, and 129 CRS patients who exposed to air conditioning everyday), exposure to mould or damp environments ( 45 for CRS patients who exposed everyday, 137 who exposed frequently)

Smoking (34 patients having sinusitis), injury exposure (185 having sinusitis), nasal deformities (29), exposure to pollution(34), immune system disturbance (15), aspirin sensitivity (7), allergy (151), bronchial asthma (28), medical and non-medical jobs

In-house domestic pets (cats or dogs, birds) (63 patients with fungal CRS and 144 with non-fungal CRS) cockroaches in house (37 patients with fungal CRS and 40 with non-fungal CRS), carpets (80 fungal CRS, 31 non-fungal CRS), exposure to plants (10 with fungal CRS, 62 with non-fungal CRS), exposure to dust at home or workplace (69 with fungal CRS, 12 with non-fungal CRS), residents in $>30$-year-old house ( 26 with fungal CRS, 2 with non-fungal CRS), Resident in overcrowded house floor space per person below $\leq 26$ meter ( 27 with fungal CRS, 2 with non-fungal CRS), poor exposure to sun (93 with fungal CRS, 47 with non-fungal CRS)

Exposure to animals at work, smoking (24\%), paper dust, metal dust, animals, moisture/mould/mildew.

No more data on percentage for each exposure.

Dampness (11.3\%), smoking, wood stoves as principal source of heat and exposure to gas, fumes, and dust at work.

No more data about percentage for each exposure.

Smoking (712 CRS patients), allergic rhinitis, asthma, and atopic dermatitis, septal deviation, chronic otitis media, rural (368) or urban (1133) residence, blue-collar (1036) white-collar (464) occupation, heavy (475) or light stress (1026) level, presences (305) or absence (1207) suicidal ideation, obesity being overweight (528) or normal and less (973), and alcohol consumption twice a week or more (416) or less than twice a week (1084).

No more data on percentage for each exposure.

CRS: chronic rhinosinusitis, EPOS: European Position Paper on Rhinosinusitis and Nasal Polyps 
Table 1 - Characteristics of the included studies in terms of number of patients,method of diagnosis and exposure to environmental and occupational factors (continuation).

\begin{tabular}{lcl}
\hline Reference/year & $\begin{array}{c}\text { Number of } \\
\text { patients }\end{array}$ & Diagnosis methods \\
\hline $\begin{array}{l}\text { Koh et al, }{ }^{15} \\
2009\end{array}$ & 945 & $\begin{array}{l}\text { A questionnaire based on previously diagnosed } \\
\text { CRS }\end{array}$
\end{tabular}

Thilsing et al, ${ }^{16} \quad 243 \quad$ Diagnosis based on EPOS

2012 Veloso-Teles et $\quad 19 \quad$ Diagnosis based on EPOS
al, ${ }^{17} 2018$

Kajiwara-Morita $\quad 275$ et al, ${ }^{18}$

2018

Putman et al, ${ }^{19}$ 2018

Subjective and objective assessment for diagnosis of CRS

Clarhed et al, ${ }^{20}$ 2020

Questionnaire based on EPOS guideline

A questionnaire based on previously diagnosed CRS

Velasquez et $\mathrm{al}^{21}$ on the International Consensus Statement on Allergy and Rhinology of CRS

5848 A questionnaire based on sinusitis symptoms
Occupation and environmental exposure

Plant or machine operators and assemblers (881 for men and 57 for women), craft and related trades workers (1387 for men and 282 for women), skilled agricultural or forestry or fishery workers (1045 for men and 1068 for women), sales workers and service workers (1857 for men and 1923 for women), technician and associated professionals (546 for men and 279 for women), professionals (499 men, 279 women), clerical workers (1477 men, 830 women) Exposure to high-molecular weight agents as (animal dander, fish or shellfish, plant antigen, mites and insects, latex, enzymes, bio aerosols, pharmaceutical products) (6.2\%), low-molecular weight agents as (Highly reactive chemicals, isocyanides, reactive cleaning disinfection, wood dust, metal and metal fumes (9.3\%), mixed exposure environments as (agricultural, textile production, metal work, irritant peaks) (6\%), and low asthma risk agents (environmental tobacco smoke, exhaust, low-risk irritants, or jobs with low levels of exposure to asthmagens), occupational exposure to gasses or fumes or dust or smoke.

No more data on percentage for each exposure

Smoking, alcohol exposure, work sector (spinning $10.5 \%$ with nasal polyps, $20.4 \%$ with no nasal polyps), wrapping (5.3\% with nasal polyps, $7.3 \%$ with no nasal polyps), weaving $(26.3 \%$ with nasal polyps, $15.3 \%$ with no nasal polyps), dyeing (10.5\% with nasal polyps and $9.2 \%$ with no nasal polyps), finishing ( $21.1 \%$ with nasal polyps and $27.6 \%$ with no nasal polyps), quality control (5.3\% with nasal polyps and $3.6 \%$ with no nasal polyps), storing and packing ( $10.5 \%$ with nasal polyps and $7.1 \%$ with no nasal polyps), informatics and marketing ( $0 \%$ with nasal polyps and $3.1 \%$ with no nasal polyps), administration ( $0 \%$ with nasal polyps, $4.1 \%$ with no nasal polyps), designing ( $5.3 \%$ with nasal polyps and $1.5 \%$ with no nasal polyps), wood work ( $5.3 \%$ with nasal polyps and $0.5 \%$ with no nasal polyps), exposure to domestic fumes (such as: using coal or fire-wood) and domestic animals.

Smoking (32.1\% current smokers), alcohol consumption( 30.6\% who drink alcohol more than 3 times a week, $33.1 \%$ who drink alcohol 1-3 times a week), living on a farm (33.6\%), exposure to grain dust $(33.2 \%)$, mine dust $(34.5 \%)$, wood dust $(35.1 \%)$, diesel fumes $(34.1 \%)$, radiation $(42.8 \%)$ and mold $(41.8 \%)$. Allergies such as mold allergies $(62 \%)$, grass allergies $(58.7 \%)$, and pollen $(59.3 \%)$.

prolonged irritant exposure as defined by working at the $\mathrm{WTC}^{3}$ site of 6 months or more ( $p=1.08$ to- 1.34 for $2-5$ month exposure compared to $p=1.31$ to 1.65 for $>6$ months exposure), exposure to components found in WTC dust, such as metals, and smoking.

No more data on percentage for each exposure

Presence $(n=170,9 \%)$ or absence $(n=205,4 \%)$ of atopy, presence $(n=65,10 \%)$ or absence $(n=310,5 \%)$ of asthma, current $(n=103$, $7 \%)$ or past $(n=85,5 \%)$ or never $(n=187,5 \%)$ smokers, gas exposure such as cooking fumes, strong acids, dust exposure such as wood, paper, metal dusts, cleaning agents, hair care products, and a cold work environment

No more data on percentage for each exposure

Subjective and Objective diagnosis for CRS based Diesel exposure, exposure to vapors, gases, dusts, fumes, fibers and mists (VGDFFIM) (48.60\% CRS patients without nasal polyps, $63.50 \%$ CRS patients with nasal polyps)

Smoking (contain ammonia) and dust exposure $(n=1)$.
Current $(n=1523,30 \%)$, former $(n=1466,30 \%$, never $(n=2854$, 27.9\%) tobacco smoking 
higher rates of hyposmia ( $16 \%$ versus $5 \%, p=0.003$ ), facial pressure ( $38 \%$ vs. $24 \%, p=0.008)$, and sneezing $(62 \%$ vs. $38 \%, p<0.001)$, headache $(38 \%$ vs. $22 \%$, $p=0.003)$ and nasal pruritus (61\% vs. $37 \%, p<0.001)$ as mentioned by Veloso-Teles. ${ }^{17} \mathrm{CRS}$ is classified into 2 categories based on the presence or absence of nasal polyps. The prevalence of CRS ranges between $6 \%$ and $27.1 \%$; the prevalence of CRS in the United States is $12 \%$ and in Europe is $10.9 \%$. However, the prevalence of CRS in Saudi Arabia is 25.3\%. There was a significant increase in the prevalence of CRS in machinery and plant operators. It is evident that CRS is associated with impaired quality of life, declining productivity at work, and unaffordable medical treatments. Furthermore, it has a negative effect on patients' health by causing sleep disturbances, depression, sexual dysfunction, and anxiety. Different diagnostic methods of CRS were used in the articles included in our systematic review; 8 of those articles used the European Position Paper on Rhinosinusitis and Nasal Polyps as the method of diagnosis by fulfilling the European Position Paper on Rhinosinusitis and Nasal Polyps adult criteria in a questionnaire. While 2 articles used the methods of diagnosis based on a questionnaire, which was based on previously diagnosed cases of CRS, 2 other articles utilized subjective and objective assessment for the diagnosis of CRS. While one article adopted subjective and objective assessment for diagnosis of CRS based on the International Consensus Statement on Allergy and Rhinology, another article utilized a survey including 20 questions to investigate the sociodemographic and risk factors of chronic sinusitis as the diagnostic method, and finally one article used a questionnaire based on sinusitis symptoms.

In this study, we found that environmental factors play a significant pathogenic role in the development of CRS. Our data showed that smoking ( $\mathrm{n}=9734,10 \%)$ was positively associated with CRS. There is a $44 \%$ higher risk for CRS development among smokers in comparison to non-smokers as illustrated by Clarhed et al. ${ }^{20}$ According to Chen et al, ${ }^{24} \mathrm{CRS}$ is more prevalent in current smokers $(n=1000,12 \%)$ than former smokers $(\mathrm{n}=1057,10 \%)$. On the contrary, Chen et $\mathrm{al}^{24}$ confirmed that active female smokers $(n=654,7.6 \%)$ were at a greater risk for CRS than active male smokers $(n=347$, $4.2 \%$ ). Hur et $\mathrm{a}^{25}$ found a statistically significant relation between passive smoking and CRS; however, Wentzel et $\mathrm{al}^{26}$ found equal passive smoke exposure between CRS and control group. Therefore, Christensen et $\mathrm{al}^{27}$ concluded that there is no clear evidence supporting the association between secondhand smoke exposure and CRS. Residents of urban $(\mathrm{n}=4234,4 \%)$ areas were at a lower risk for CRS. According to Kajiwara-Morita, farmers were more likely to develop CRS compared to non-farmers. This finding is supported by the heavy use of fungicide, pesticides, and insecticide $(n=4248$, $4 \%)$ in their residential areas. ${ }^{18}$ Similarly, Yu et $\mathrm{al}^{28}$ found that Asian sand dust (ASD), carried through wind from the Mongolian deserts, is associated with the development of CRS and other respiratory diseases. Yeo et $\mathrm{al}^{29}$ described the mechanism by which ASD leads to CRS as ASD increases the replication of rhinovirus leading to disturbance in the local immunological environment, rendering the nasal mucosa more susceptible to dust and microbes. However, Min et al ${ }^{30}$ and Hoffmans et $\mathrm{al}^{31}$ found no relation between the place of residence and prevalence of CRS. Sundaresan et $\mathrm{al}^{32}$ reported that because of the lack of precision of most studies regarding occupational exposure, no accurate conclusion can be deduced. However, Velazquez et $\mathrm{al}^{21}$ found a linear relationship between occupational exposure to gases vapor, dust, fibers, fumes, and mists $(n=150,1 \%)$ and the need for corticosteroids and functional endoscopic sinus surgery in patients with CRS ( $n=63,0.6 \%)$, which is in agreement with our findings. Moreover, we found that individuals with blue-collar occupations $(n=5260,5.4 \%)$ have a greater potential to acquire CRS than those with white-collar occupations ( $\mathrm{n}=1176,1.22 \%)$, which is consistent with Thilsing et $\mathrm{al}^{16}$ findings. Koh et $\mathrm{al}^{15}$ reported that plant and machine operators and assemblers $(n=75$, $0.077 \%)$, craft workers ( $\mathrm{n}=87,0.09 \%)$, and elementary occupations $(\mathrm{n}=110,0.11 \%)$ were at a greater risk to develop CRS based on data acquired from the Korea National Health and Nutrition Examination Surveys. In contrast, we found that firefighters $(n=2353,2.4 \%)$ were at the greatest risk for CRS, which is supported by Webber et $\mathrm{al}^{33}$ based on a cumulative analysis of studies conducted on various countries. In addition, farmers and fishermen $(\mathrm{n}=1184,1 \%)$ directly follow firefighters, as supported by Siracusa et al. ${ }^{34}$

Study limitations. This study exhibited that we rely on studies that have subjective or objective diagnosis of CRS, also there is no local studies available which will have an impact on relation between CRS and environmental exposures in our community, and lastly it's preferred to be carried out along with meta-analysis. Future meta-analysis needs to be conducted to provide further evidence regarding these findings. Also, local studies need to be carried out to evaluate this relation in our community.

In conclusion, CRS is a chronic inflammatory disease of the paranasal sinuses, affected by several environmental and occupational factors. We found that 
smoking was the most aggravating environmental factor followed by exposure to pesticides, which is observed in rural areas. The severity of CRS symptoms tends to increase with direct contact with allergens. Thus, the greatest proportion of patients with CRS is those with blue-collar occupations, including firefighters, farmers, and fishermen.

Acknowledgment. The authors gratefully acknowledge Editage (www.editage.com) for English language editing.

\section{References}

1. Gao WX, Ou CQ, Fang SB, Sun YQ, Zhang H, Cheng L, et al. Occupational and environmental risk factors for chronic rhinosinusitis in China: a multicentre cross-sectional study. Respir Res 2016; 17: 1-7.

2. Rosenfeld RM, Andes D, Bhattacharyya N, Cheung D, Eisenberg S, Ganiats TG, et al. Clinical practice guideline: adult sinusitis. J Otolaryngol-Head N 2007 1; 137: S1-31.

3. Homood MA, Alkhayrat SM, Kulaybi KM, Mohajer AA, Majrashi AS, Salawi AA, et al. Prevalence and risk factors of chronic sinusitis among people in Jazan Region' KSA. Egypt J Hosp Med 2017; 69: 2463-2468.

4. Abualnasr SA, Alattas AM, Abualnasr AA, Alsrisri HA, Aljeraisi T. Prevalence of chronic rhino sinusitis and it's recurrent after treatment compare to its recurrent after surgery at Saudi Arabia. Int J Adv Res 2016; 5: 2310-2318.

5. Hussein A, Obaid A, Lotfi WT, Mostafa HS. Prevalence, Demographic and environmental factors of allergic fungal sinusitis among chronic sinusitis patients with nasal polyps in western Saudi Arabia. Pan Arab J Rhinol 2019; 9: 26-30.

6. Fu QL, Ma JX, Ou CQ, Guo C, Shen SQ, Xu G, et al. Influence of self-reported chronic rhinosinusitis on health-related quality of life: a population-based survey. PloS one 2015; 10: e0126881.

7. Van Crombruggen K, Zhang N, Gevaert P, Tomassen P, Bachert C. Pathogenesis of chronic rhinosinusitis: inflammation. J Allergy Clin Immunol 2011;128: 728-732.

8. Smith DF, Ishman SL, Tunkel DE, Boss EF. Chronic rhinosinusitis in children: race and socioeconomic status. $J$ Otolaryngol-Head N 2013; 149: 639-644.

9. Soler ZM, Mace JC, Litvack JR, Smith TL. Chronic rhinosinusitis, race, and ethnicity. Am J Rhinol Allergy 2012; 26: $110-116$.

10. Hellgren J, Lillienberg L, Jarlstedt J, Karlsson G, Torén K. Population-based study of non-infectious rhinitis in relation to occupational exposure, age, sex, and smoking. Am J Ind Med 2002; 42: 23-28.

11. Hox V, Steelant B, Fokkens W, Nemery B, Hellings PW. Occupational upper airway disease: how work affects the nose. Allergy 2014; 69: 282-291.

12. Clarhed UK, Svendsen M, Schiöler L, Kongerud J, Torén K, Hellgren J, et al. Chronic rhinosinusitis related to occupational exposure: the telemark population study. J Occup Environ Med 2018; 60: 656-660.

13. Ahlroth Pind C, Gunnbjörnsdottír M, Bjerg A, Järvholm B, Lundbäck B, Malinovschi A, et al. Patient-reported signs of dampness at home may be a risk factor for chronic rhinosinusitis: A cross-sectional study. Clin Exp Allergy 2017; 47: 1383-1389.
14. Hwang CS, Lee HS, Kim SN, Kim JH, Park DJ, Kim KS. Prevalence and risk factors of chronic rhinosinusitis in the elderly population of Korea. Am J Rhinol Allergy 2019; 33: 240-246.

15. Koh DH, Kim HR, Han SS. The relationship between chronic rhinosinusitis and occupation: the 1998, 2001, and 2005 Korea National health and nutrition examination survey (KNHANES). Am J Ind Med 2009; 52: 179-184.

16. Thilsing T, Rasmussen J, Lange B, Kjeldsen AD, Al-Kalemji A, Baelum J. Chronic rhinosinusitis and occupational risk factors among 20-to 75-year-old Danes-A GA2LEN-based study. A J Ind Med 2012; 55: 1037-1043.

17. Veloso-Teles R, Cerejeira R, Roque-Farinha R, von Buchwald C. Higher prevalence of nasal polyposis among textile workers: an endoscopic based and controlled study. Rhinology 2018; 56 : 99-105.

18. Kajiwara-Morita A, Karunanayake CP, Dosman JA, Lawson JA, Kirychuk S, Rennie DC, et al. Prevalence and determinants of sinus problems in farm and non-farm populations of Rural Saskatchewan, Canada. Sinusitis 2018; 3: 2.

19. Putman B, Zeig-Owens R, Singh A, Hall CB, Schwartz $\mathrm{T}$, Webber MP, et al. Risk factors for post-9/11 chronic rhinosinusitis in Fire Department of the City of New York workers. Occup Environ Med 2018; 75: 884-889.

20. Clarhed UK, Johansson H, Svendsen MV, Torén K, Møller Fell AK, Hellgren J. Occupational exposure and the risk of new-onset chronic rhinosinusitis-a prospective study 2013-2018. Rhinology 2020; 58: 597-604.

21. Velasquez N, Moore JA, Boudreau RM, Mady LJ, Lee SE. Association of air pollutants, airborne occupational exposures, and chronic rhinosinusitis disease severity. Int Forum Allergy Rhinol 2020; 10: 175-182.

22. Brautbar N. Ammonia Exposure: A common cause for sinusitis a case report and review of the literature. Toxicol Ind Health 1998; 14: 891-895.

23. Lieu JE, Feinstein AR. Confirmations and surprises in the association of tobacco use with sinusitis. Arch Otolaryngol Head Neck Surg 2000; 126: 940-946.

24. Chen Y, Dales R, Lin M. The epidemiology of chronic rhinosinusitis in Canadians. Laryngoscope 2003; 113: 1199-1205.

25. Hur K, Liang J, Lin SY. The role of secondhand smoke in sinusitis: a systematic review. Int Forum Allergy Rhinol 2014; 4: 22-28.

26. Wentzel JL, Mulligan JK, Soler ZM, White DR, Schlosser RJ. Passive smoke exposure in chronic rhinosinusitis as assessed by hair nicotine. Am J Rhinol Allergy 2014; 28: 297-301.

27. Christensen DN, Franks ZG, McCrary HC, Saleh AA, Chang EH. A systematic review of the association between cigarette smoke exposure and chronic rhinosinusitis. Otolaryngol Head Neck Surg 2018; 158: 801-816.

28. Yu HL, Chien LC, Yang CH. Asian dust storm elevates children's respiratory health risks: a spatiotemporal analysis of children's clinic visits across Taipei (Taiwan). PLoS One 2012; 7: e41317.

29. Yeo NK, Hwang YJ, Kim ST, Kwon HJ, Jang YJ. Asian sand dust enhances rhinovirus-induced cytokine secretion and viral replication in human nasal epithelial cells. Inhal Toxicol 2010; 22: 1038-1045.

30. Min YG, Jung HW, Kim HS, Park SK, Yoo KY. Prevalence and risk factors of chronic sinusitis in Korea: results of a nationwide survey. Eur Arch Otorhinolaryngol 1996; 253: 435-439. 
31. Hoffmans R, Wagemakers A, van Drunen C, Hellings P, Fokkens W. Acute and chronic rhinosinusitis and allergic rhinitis in relation to comorbidity, ethnicity and environment. PloS one 2018; 13: e0192330.

32. Sundaresan AS, Hirsch AG, Storm M, Tan BK, Kennedy TL, Greene JS, et al. Occupational and environmental risk factors for chronic rhinosinusitis: a systematic review. Int Forum Allergy Rhinol 2015; 5: 996-1003.
33. Webber MP, Glaser MS, Weakley J, Soo J, Ye F, Zeig-Owens $\mathrm{R}$, et al. Physician-diagnosed respiratory conditions and mental health symptoms 7-9 years following the World Trade Center disaster. Am J Ind Med 2011; 54: 661-671.

34. Siracusa A, Desrosiers M, Marabini A. Epidemiology of occupational rhinitis: prevalence, aetiology and determinants. Clin Exp Allergy 2000; 30: 1519-1534. 